\title{
Egzersiz Temelli Kardiyak Rehabilitasyon Programının Koroner Arter Hastalarında Fonksiyonel Kapasite, Kinezyofobi Düzeyi ve Yaşam Kalitesi Üzerine Etkisi
}

\section{Effect of Exercise-Based Cardiac Rehabilitation Program on Functional} Capacity, Kinesiophobia Level and Quality of Life in Patients with Coronary Artery Disease

\author{
İsmail OKUR ${ }^{1 *(1)}$, Cihan Caner AKSOY1 ${ }^{10}$, Fatıma YAMAN ${ }^{2}$ (D) Taner ŞEN $^{3}$ (D) \\ ${ }^{1}$ Kütahya Sağlık Bilimleri Üniversitesi, Sağlık Bilimleri Fakültesi, Fizyoterapi ve Rehabilitasyon Bölümü, Kütahya, Türkiye \\ ${ }^{2}$ Kütahya Sağlık Bilimleri Üniversitesi, Tıp Fakültesi, Fiziksel Tıp ve Rehabilitasyon AD, Kütahya, Türkiye \\ ${ }^{3}$ Kütahya Sağlık Bilimleri Üniversitesi, Tıp Fakültesi, Kardiyoloji AD, Kütahya, Türkiye
}

\begin{abstract}
Ö Z E T
Amaç: Bu çalışma, egzersiz temelli kardiyak rehabilitasyon (ETKR) programının koroner arter hastalarının fonksiyonel kapasite, kinezyofobi düzeyi ve yaşam kaliteleri üzerine etkisini incelemek üzere planlanmıştır.
\end{abstract}

Materyal-Metod: Çalışmaya 22 koroner arter hastası (yaş ortalamaları 60,72 $\pm 5,28$ yıl) dahil edildi. Katılımcılar 5 hafta ve 5 seans/hafta bisiklet ergometrisi ile egzersiz eğitim programına tabi tutuldu. Katılımcıların fonksiyonel kapasiteleri 6 dakika yürüme testi (6DYT), kinezyofobi düzeyleri Tampa Kinezyofobi Ölçeği- Kalp versiyonu (TKÖ-K) ve yaşam kaliteleri ise Kısa Form-36 (KF-36) ve Macnew Kalp Hastalığı Sağlıkla İlgili Yaşam Kalitesi Ölçeği (MYKÖ) kullanılarak değerlendirildi. Tüm değerlendirmeler ETKR öncesi ve sonrasında gerçekleştirildi.

Bulgular: Katılımcıların 6DYT mesafeleri tedavi öncesi ve sonrası sırasıyla $524,55 \pm 67,78 \mathrm{~m}$ ve $561,68 \pm 68,39 \mathrm{~m}$ olarak ölçüldü ve aradaki fark istatistiksel olarak anlamlıydı $(p<0,001)$. TKÖ-K skorundaki tedavi sonrası ve tedavi öncesi arasındaki değişim istatistiksel olarak anlamlı değildi $(p=0,191)$. Ancak kinezyofobi düzeyi yüksek olan katılımcı sayısının istatistiksel olarak anlamlı azaldığı tespit edildi $(p=0,035)$. Yaşam kalitesi verilerinde KF-36'nın fiziksel fonksiyon ve ağrı alt başlıklarında, MYKÖ'nün ise tüm alt başlıklarında istatistiksel olarak anlamlı iyileşme olduğu bulundu $(p<0,05)$.

Sonuç: Bu çalışma sonuçları ETKR programının koroner arter hastalarında fonksiyonel kapasite, kinezyofobi düzeyi ve yaşam kalitesini iyileştirmede etkili olduğunu göstermektedir. Bu çalışma ETKR programının kinezyofobi düzeyi üzerine etkisini inceleyen bilgimiz dahilindeki ilk çalışmadır. Kinezyofobi düzeyinin belirlenmesinin ve tedavi programlarını bu doğrultuda şekillendirilmesinin rehabilitasyon çıktıları üzerine olumlu etki edeceğini düşünmekteyiz.

Anahtar Kelimeler: Kardiyak rehabilitasyon, egzersiz testi, yaşam kalitesi, koroner arter hastalığı, kinezyofobi

Alınış / Received: 01.09.2021 Kabul / Accepted: 23.11.2021 Online Yayınlanma / Published Online: 20.12.2021 


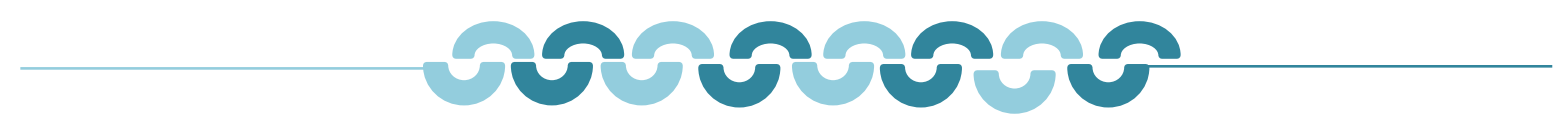

\author{
A B S T R A C T
}

Objective: This study was planned to examine the effect of exercise-based cardiac rehabilitation (EBCR) program on functional capacity, kinesiophobia level and quality of life on patients with coronary artery disease.

Material and Method: A total of 22 patients with coronary artery disease (the mean age $60.72 \pm 5.28$ years) were included in the study. Participants were recruited to exercise training programme with cycle ergometer for 5 weeks and 5 sessions/week. Functional capacities of participants were evaluated with the 6-minute walk test (6MWT), kinesiophobia levels with the Tampa Kinesiophobia Scale- Heart version (TKS-H), and quality of life with the Short Form-36 (SF-36) and the Macnew Heart Disease Health-Related Quality of Life Scale (Macnew). All evaluations were performed before and after the EBCR.

Results: The 6MWT distances of the participants pre- and post-treatment were measured as $524.55 \pm 67.78 \mathrm{~m}$ and $561.68 \pm 68.39 \mathrm{~m}$, respectively, and the difference was statistically significant $(p<0.001)$. The post- and pretreatment difference in the TKS-H score was not statistically significant $(p=0.191)$, however it was determined that there was a statistically significant decrease in the participants with high kinesiophobia levels $(p=0.035)$. It was found that SF-36 had a statistically significant improvement in physical function and pain, and in all subtitles of Macnew $(\mathrm{p}<0.05)$.

Conclusions: The results of this study showed that EBCR is effective in improving functional capacity, kinesiophobia level and quality of life in patients with coronary artery disease. To our knowledge, this study is the first study examines the effect of EBCR program on kinesiophobia level. We thought that determining the level of kinesiophobia and planning the treatment programs accordingly, will have a positive effect on rehabilitation outcomes.

\title{
1. Giriş
}

Koroner Arter Hastalığı (KAH), ülkemizde, Avrupa'da ve dünyada önde gelen mortalite nedenleri arasında yer almaktadır [1-3]. Avrupa'da 2016 yılında KAH 1,7 milyon ölüme yol açmıştır [2]. Ülkemizde 2016 yılında gerçekleştirilen Türk Erişkinlerinde Kalp Hastalığı ve Risk FaktörleriTEKHARF çalışmasında; tüm ölümlerin \% 42'sinin koroner nedenlerle gerçekleştiği ve KAH'ın en önemli ölüm nedenlerinden biri olduğu gösterilmiştir. Aynı çalışmada 20 yaş ve üzeri bireylerde yıllık mortalite, nüfusun binde 11,4'ü (erkeklerde binde 13,5, kadınlarda binde 9) olarak hesaplanmıştır [3]. Bunun yanında Avrupa'da KAH kaynaklı sağlık giderleri ve iş gücü kaybının maliyeti yıllık 196 milyon avro olarak hesaplanmıştır [4].

KAH bireylerin yaşamlarını önemli ölçüde etkilemektedir. KAH'ın hastaların fonksiyonel kapasiteleri [5], kinezyofobi düzeyleri [6] ve yaşam kaliteleri [7] üzerine olumsuz etkilerinin olduğu ve bu etkilerin hastalık şiddetiyle paralel olarak arttığı yapılan araştırmalarla ortaya konmuştur. KAH hastalarında fonksiyonel kapasite [8] ve yaşam kalitesinin [9] sağ kalım için önemli bir belirleyici olduğu, KAH hastalarının kinezyofobi düzeylerinin yüksek olduğu ve bu durumun rehabilitasyon çıktılarını olumsuz yönde etkilediği bildirilmiştir [10]. Bu nedenle tedavi programlarının bu faktörler üzerine olan etkisinin belirlenmesi ve tedavinin bu doğrultuda şekillendirilmesi büyük önem taşımaktadır [11].

$\mathrm{KAH}$ tedavisinde kardiyak olay/cerrahi öncesi, hastane dönemi ve kardiyak olay/cerrahi sonrasında, her aşamada kullanılabilecek tedavi seçeneklerinden birisi egzersiz temelli kardiyak rehabilitasyon (ETKR)'dur. ETKR'nin KAH'da fiziksel kapasiteyi arttırması, mortaliteyi ve katıım kısıtlııklarını önemli 
ölçüde azaltması nedeniyle Amerikan Kalp Birliği ve Avrupa Kardiyoloji Derneği tarafından yüksek kanıt düzeyine sahip öneri olarak gösterilmektedir [12].

Literatürde ETKR programın sonrası fonksiyonel kapasite ve yaşam kalitesindeki değişimleri gösteren çalışmalar bulunmasına karşın [13,14], ETKR programının kinezyofobi düzeyi üzerine etkisini inceleyen çalışmaya rastlanmamıştır. Bu nedenle çalışmamız, ETKR programının KAH hastalarının fonksiyonel kapasite, kinezyofobi düzeyi ve yaşam kaliteleri üzerine etkisini incelemek üzere planlanmıştır.

\section{Materyal ve Metot}

Çalışma, T.C. Sağlık Bakanlığı Kütahya Sağlık Bilimleri Üniversitesi Evliya Çelebi Eğitim Araştırma Hastanesi FTR Ek Hizmet Binası'nda yer alan Kardiyopulmoner Rehabilitasyon ünitesinde gerçekleştirildi. Çalışma verileri Temmuz 2019-Nisan 2021 tarihleri arasında toplandı. Bu çalışma, Kütahya Sağlık Bilimleri Üniversitesi Klinik Araştırmalar Etik Kurulu tarafından 13.06.2019 tarihli 2019/05 sayılı karar ile onaylandı.

\section{Katılımcılar}

Çalışmaya yaşı 50-75 yaşları arasında olan, perkutan koroner girişim veya koroner arter bypass greft (KABG) cerrahisi geçirmiş, sol ventrikül ejeksiyon fraksiyonu \%50 üzerinde olan, 2 haftadan uzun süredir klinik olarak stabil olan ve çalışmada yer almaya gönüllü olan katılımcılar dahil edildi. İskemi semptomları olan, New York Kalp Sınıflamasına göre Sınıf III-IV'te olan, tam katılımı engelleyen belirgin ortopedik veya nörolojik komorbiditesi bulunan, ventriküler aritmisi olan, belirgin valvular kalp hastalığı bulunan ve tedavi programına $\% 80$ 'den az katıım gösteren hastalar ise çalışmaya dahil edilmedi.

\section{Prosedür}

ETKR programına dahil olmak üzere Kardiyopulmoner Rehabilitasyon ünitesine başvuran toplam 57 hasta dahil edilme ve dışlama kriterleri açısından değerlendirildi. KAH tanısı olmayan 16 hasta, sol ventrikül ejeksiyon fraksiyonu \%50 altında olan 11 hasta, revaskülarizasyon cerrahisi geçirmemiş 4 hasta, New York Kalp Sınıflamasına göre Sınıf III-IV'te olan 1 hasta, ventriküler aritmisi olan 1 hasta, belirgin valvular kalp hastalığı olan 1 hasta ve nörolojik sekeli olan 1 hasta çalışma alınmadı. Çalışma hakkında gerekli bilgilendirmeler yapıldıktan sonra, çalışmada yer almayı kabul eden katılımcılara aydınlatımış onam formunu okuyarak imzalamaları istendi. Dahil edilme kriterlerini karşılayan 22 katıımcı 4-8 kişilik gruplar halinde, 24 seans bisiklet ergometrisi programına dahil edildi. Katıımcılar hastaneye başvurdukları ilk gün değerlendirmeye tabi tutuldu ve ertesi gün 24 seanslık ETKR programına alındı. Egzersiz 5 seans/hafta olacak şekilde 5 hafta sürdürüldü. Katılımcıların tabi olacakları iş yükü, maksimal egzersiz testi ile belirlenen maksimum iş yükü (Wmax) üzerinden hesaplandı. Katılımcılar belirlenen maksimal iş yükünün \%50-70'i arasında orta yoğunlukta sürekli eğitime (Wmax'ın \%50-70'inde) ya da yüksek yoğunluklu aralıklı eğitime (Wmax'ın \%80-100'ünde yüklenme, Wmax'ın \%50-70'inde aktif toparlanma) tabi tutuldu. Egzersiz eğitimleri ısınma ve soğuma periyotları dahil 30-45 dakika arasında sürdü. Ayrıca tüm katılımcılar 2 seans/hafta 1 maksimum tekrarın \%60-80'inde submaksimal dirençli egzersiz programına alındı. Bu programda büyük kas grupları arasında yer alan ve günlük yaşam aktivitelerinde etkili olan quadriceps, hamstring, deltoid, latissumus dorsi, biceps ve triceps kasları hedef alındı [15]. Hastaların bisiklet ergometrisi egzersiz programı ve kuvvetlendirme eğitimi sırasında tabi tutulduğu egzersiz şiddeti, 6-20 arası puanlanan Borg ile sorgulanarak dereceli olarak arttırıldı.

\section{Değerlendirmeler}

Katılımcıların fonksiyonel kapasiteleri 6 dakika yürüme testi (6DYT), kinezyofobi düzeyleri Tampa Kinezyofobi Ölçeği- Kalp versiyonu (TKÖ-K), yaşam kaliteleri ise Kısa Form-36 (KF-36) ve Macnew Kalp Hastalığı Sağıkla İlgili Yaşam Kalitesi Ölıceği (MYKÖ) kullanılarak, ilk seansta ve 24 seans ETKR programını tamamladıktan sonra değerlendirildi. İlk seansta 6DYT sonrası hasta 30 dakika dinlendirilip yorgunluk algısı başlangıç düzeyine ulaştıktan sonra maksimal egzersiz testine alındı. Maksimal egzersiz testi sonrası ilgili anketler uygulandı. 
Katılımcılar ilk seansta maksimal egzersiz testine tabi tutuldu. Maksimal egzersiz testi, Ergoline bisiklet ergometresi (Ergoline $\mathrm{GmbH}$, Bitz, Germany) kullanılarak gerçekleştirildi ve her katıımcının fiziksel kapasitesine uygun olarak dakikada 10,15 ya da 20 wattlık artışlardan oluşan egzersiz test protokolü uygulandı [16]. Test 8-12 dakika arasında maksimal kalp hızına ulaşılması veya hastanın testi daha fazla sürdürememesi nedeniyle sonlandırıldı. Bu çalışmada yapılan maksimal egzersiz testleri sırasında herhangi bir kardiyak olay gerçekleşmedi.

Katıımcıların fonksiyonel kapasitelerinin değerlendirilmesinde 6DYT kullanıldı. 6DYT kardiyak popülasyonda geçerli ve güvenilir, uygulaması kolay, teknolojik donanım gerektirmeyen ve günlük aktivitelerle ilişkili bir değerlendirme yöntemidir [17]. Test 30 metrelik bir koridorda gerçekleştirildi. Katılımcılardan 6 dakika boyunca olabildiğince hızlı yürümeleri istendi. Test öncesi ve sonrası kalp hızı, kan basıncı, solunum frekansı, satürasyon, Borg skalası ile yorgunluk ve dispne algısı kaydedildi. Yürüme mesafesi test çıktısı olarak metre cinsinden kaydedildi. Gremeaux ve ark. [18] (2011) tarafından testin KAH hastaları için minimal klinik anlamılığı 25 metre olarak hesaplamıştır.

Çalışmada yer alan katılımcıların kinezyofobi düzeyleri TKÖ-K kullanılarak belirlendi. TKÖ-K, hareket/tekrar yaralanma korkusunu değerlendirmek üzere geliştirilmiş, 17 sorudan oluşan bir ölçektir. Ölçeğin kalp hastalarında Türkçe geçerlilik güvenirliliği ise Acar ve ark. [19] tarafından gerçekleştirilmiştir. Ölçek 4'lü likert puanlamasına göre oluşturulmuştur (1=Kesinlikle katılmıyorum, 4=Tamamen katılıyorum). Ankette yer alan 4, 8, 12 ve 16. maddeler ters çevrilir ve tüm cevaplar toplanarak toplam skor elde edilir. Toplam skor 17-68 arasındadır. Skor arttıkça, kinezyofobi düzeyi de artmaktadır. Buna ek olarak, toplam TKÖ-K skoru 37'nin üzerinde olanların yüksek seviye kinezyofobi düzeyine sahip oldukları kabul edilmektedir [20].

Sağıkla ilgili yaşam kalitesini değerlendirmek üzere, yaygın olarak kullanılan ve KAH hastalarında güvenilirliği bulunan KF-36 Sağlık Taraması Versiyon 2 kullanıldı [21]. Anketin ikinci versiyonunun geçerlilik çalışması Çelik ve Çoban (2016) tarafından yapılmıştır [22]. KF-36, genel sağlık, fiziksel fonksiyon, fiziksel rol, emosyonel rol, sosyal fonksiyon, ağrı, enerji ve mental sağlık olmak üzere sekiz alt ölçekten oluşmaktadır. Her bir alt ölçek için 0-100 arasında puanlama yapılmaktadır. Düşük puan, kötü sağlık durumunu göstermektedir [21].

Katıııcıların kalp hastalığı ile ilgili yaşam kalitelerinin değerlendirilmesinde MYKÖ kullanıldı. MYKÖ'nün Türkçe geçerlilik ve güvenilirliği Daşkapan ve ark. [23] (2008) tarafından yapılmıştır. Son iki haftayı değerlendiren bu ölçek, kalp hastalığının günlük yaşam aktiviteleri, emosyonel ve sosyal fonksiyon üzerine etkisini değerlendirmek üzere geliştirilmiştir. Hastaların yanıtlarına göre 1 ile 7 arasında puanlanmaktadır. Ölçeğin, emosyonel, fiziksel, sosyal ve global olmak üzere 4 alt başlığı bulunmaktadır. Düşük puan, düşük yaşam kalitesini göstermektedir. Anketin her alt skorunda için minimal anlamlı fark 0,50 olarak hesaplanmıştır [24].

\section{İstatistiksel Analiz}

Katılımcılara ait verilerin analizinde SPSS 18.0 (SPSS Inc., Chicago, IL, USA) paket programı kullanılış̧ır. Katıımcılara verilerin aritmetik ortalamaları, tedavi sonrası-öncesi farkları $(\Delta)$ ve frekansları hesaplanmıştır. 6DYT mesafesi, 6DYT MET verileri, TKÖ-K toplam skorları, KF-36 ve MYKÖ skorlarının normal dağılıma uygunluğu Shapiro Wilk testi kullanılarak incelendi. Veriler normal dağılım göstermediği için tedavi öncesi sonrası verilerin karşılaştırılmasında Wilcoxon Signed Rank Test kullanıldı. TKÖ-K şiddetine göre dağılım yüzdelerinin karşılaştııılmasında ise Ki-kare testi kullanıldı. Etki büyüklüğü Cohen's d hesaplanarak belirlendi. Etki büyüklüğünün 0-0,19 arasında olması "ihmal edilebilir etki büyüklüğü", 0,2-0,49 arasında olması "küçük etki büyüklüğü", 0,5-0,79 arasında olması "orta etki büyüklüğü", 0,8 ve üzerinde olması ise "büyük etki büyüklüğü" olarak yorumlandı [25]. İstatistiksel anlamlılık düzeyi 0,05 olarak kabul edildi.

\section{Bulgular}

Çalışmaya $22 \mathrm{KAH}$ hastası (3 kadın, 19 erkek) dahil edilmiştir. Olguların 13 (\%59,1)'ü perkutan koroner girişim, 9 (\%40,9)'u KABG cerrahisi geçirmiştir. Katılımcılar çalışmaya kardiyak işlemden ortalama $4,91 \pm 2,18$ yıl sonra çalışmaya dahil edilmişlerdir. Katılımcılar ortalama $23,82 \pm 0,59$ seans ETKR programına alınmış ve çalışma sırasında herhangi bir komplikasyon gelişmemiştir. NYHA sınıflamasına göre Sınıf I ve Sınıf II'de sırasıyla $9(\% 41)$ ve $13(\% 59)$ katılımcı yer almaktaydı. Hastaların \%22,7'si hiç sigara içmemiş, \%59,1'i $(n=13)$ sigarayı bırakmış ve $\% 18,2$ 'si $(n=4)$ ise halen 
sigara kullanıcısıydı. Katılımcılara ait komorbid hastalıklar, ilaç kullanımı ve diğer tanımlayıcı veriler Tablo 1'de gösterildi.

Tablo 1: Katılımcıların tanımlayıcı verileri

Değişkenler $\quad \begin{aligned} & \mathrm{X} \pm \mathrm{SS} \\ & (\mathrm{N}=22)\end{aligned}$

\begin{tabular}{|c|c|}
\hline Yaş (yıl) & $60,72 \pm 5,28$ \\
\hline Boy $(\mathrm{cm})$ & $168,05 \pm 7,59$ \\
\hline Vücut ağırlığı (kg) & $84,27 \pm 13,05$ \\
\hline Vücut Kütle İndeksi (kg/m²) & $29,83 \pm 3,43$ \\
\hline Sigara tüketim miktarı (paket.yıl) & $45,24 \pm 30,51$ \\
\hline Ejeksiyon Fraksiyonu (\%) & $56,86 \pm 5,01$ \\
\hline Komorbid Hastalıklar & $\mathrm{n}(\%)$ \\
\hline Hipertansiyon & $13(59,1)$ \\
\hline Diabetes Mellitus & $9(40,9)$ \\
\hline Hiperkolesterol & $7(31,82)$ \\
\hline Kronik Obstrüktif Akciğer Hastalığı & $4(18,18)$ \\
\hline Hipotroidi & $2(9,09)$ \\
\hline \multicolumn{2}{|l|}{ Kullanılan İlaçlar } \\
\hline Betabloker & $19(86,4)$ \\
\hline Antidiyabetik & $18(81,8)$ \\
\hline Dislipidemik & $17(77,3)$ \\
\hline ACE İnhibitörü & $12(54,6)$ \\
\hline Anjiotensin II Antagonisti & $2(9,1)$ \\
\hline
\end{tabular}

Tedavi öncesi ve sonrası 6DYT mesafesi, 6DYT MET verileri ve TKÖ-K'ye ait veriler Tablo 2'de

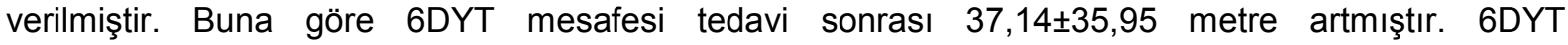
mesafesindeki bu değişimin büyük etki büyüklüğüne sahip ve istatistiksel olarak anlamlı olduğu

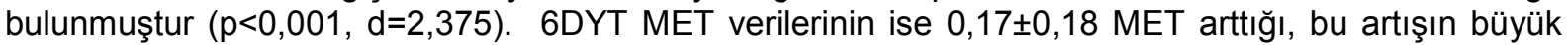
etki büyüklüğüne sahip olduğu ve artışın istatistiksel olarak anlamlı olduğu belirlenmiştir $(p=0,001$,

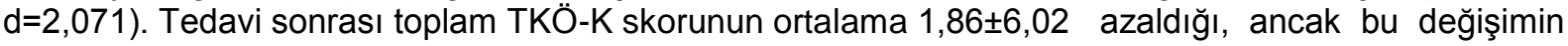
istatistiksel olarak anlamlı olmadığı tespit edilmiştir $(p=0,191, d=0,580)$. Tedavi sonrasında kinezyofobi şiddetine göre dağılımı incelendiğinde, yüksek kinezyofobi düzeyine sahip katılımcı sayısının istatistiksel olarak anlamlı azaldığı ve bu değişimin orta etki büyüklüğüne sahip olduğu bulunmuştur $(p=0,035, d=0,652)$. 
Tablo 2: 6DYT mesafesi, 6DYT (MET) ve TKÖ-K verilerinin karşılaştırılması

\begin{tabular}{|c|c|c|c|c|c|c|}
\hline \multirow[t]{2}{*}{ Değişkenler } & $\begin{array}{l}\text { Tedavi Öncesi } \\
(n=22)\end{array}$ & $\begin{array}{l}\text { Tedavi Sonrası } \\
(n=22)\end{array}$ & \multirow[t]{2}{*}{$\Delta$} & \multirow[t]{2}{*}{ Z } & \multirow[t]{2}{*}{$p$} & \multirow[t]{2}{*}{ Cohen's $d$} \\
\hline & $\mathrm{X} \pm \mathrm{SS}$ & $X \pm S S$ & & & & \\
\hline 6DYT mesafesi (metre) & $524,55 \pm 67,78$ & $561,68 \pm 68,39$ & $37,14 \pm 35,95$ & $-3,588$ & 0,000 & 2,375 \\
\hline 6DYT (MET) & $3,50 \pm 0,32$ & $3,67 \pm 0,33$ & $0,17 \pm 0,18$ & $-3,374$ & 0,001 & 2,071 \\
\hline \multirow[t]{2}{*}{ TKÖ-K Toplam Skor } & $39,82 \pm 6,07$ & $37,95 \pm 7,03$ & $-1,86 \pm 6,02$ & $-1,307$ & 0,191 & 0,580 \\
\hline & & & $\Delta$ & $x^{2}$ & $p$ & $d$ \\
\hline \multirow[t]{3}{*}{ TKÖ-K } & $5(22,7)$ & $12(54,5)$ & & & & \\
\hline & & & - & 2,111 & 0,035 & 0,652 \\
\hline & $17(77,3)$ & $10(45,5)$ & & & & \\
\hline
\end{tabular}
TKÖ-K: Tampa Kinezyofobi Ölçeği-Kalp, X: Aritmetik Ortalama, X2: Ki-kare katsayısı, Z: Wilcoxon Signed Rank Test katsayısı, $\Delta$ : Tedavi sonrası öncesi fark

Yaşam kalitesine ilişkin veriler Tablo 3'te sunulmuştur. Buna göre KF-36'nın fiziksel fonksiyon ve ağrı alt başlıklarındaki; MYKÖ'nün ise tüm alt başlıklarındaki değişimin istatistiksel olarak anlamlı olduğu belirlenmiştir $(p<0,05)$.

Tablo 3. KF-36 ve MYKÖ alt başlıklarındaki değişim

\begin{tabular}{|c|c|c|c|c|c|c|}
\hline \multicolumn{2}{|c|}{ Değişkenler } & \multirow{2}{*}{$\begin{array}{l}\text { Tedavi Öncesi } \\
(\mathrm{n}=22) \\
\mathrm{X} \pm \mathrm{SS} \\
\\
79,55 \pm 18,12\end{array}$} & \multirow{2}{*}{$\begin{array}{l}\text { Tedavi Sonrası } \\
(\mathrm{n}=22) \\
\mathrm{X} \pm \mathrm{SS} \\
86,82 \pm 11,39\end{array}$} & \multirow{2}{*}{$\begin{array}{l}Z \\
-2,314\end{array}$} & \multirow{2}{*}{$\begin{array}{l}p \\
\mathbf{0 , 0 2 1}\end{array}$} & \multirow{2}{*}{$\begin{array}{l}\text { Cohen's } d \\
1,134\end{array}$} \\
\hline \multirow{8}{*}{ KF-36 } & Fiziksel fonksiyon & & & & & \\
\hline & Fiziksel rol & $75,05 \pm 32,66$ & $82,96 \pm 28,23$ & $-1,269$ & 0,204 & 0,562 \\
\hline & Emosyonel rol & $74,25 \pm 39,75$ & $86,37 \pm 28,47$ & $-1,138$ & 0,255 & 0,500 \\
\hline & Enerji/Yorgunluk & $64,09 \pm 22,82$ & $70,91 \pm 20,45$ & $-1,638$ & 0,101 & 0,745 \\
\hline & Mental sağlık & $69,82 \pm 21,34$ & $77,82 \pm 19,51$ & $-1,549$ & 0,121 & 0,700 \\
\hline & Sosyal fonksiyon & $84,09 \pm 19,74$ & $86,25 \pm 18,38$ & $-0,314$ & 0,751 & 0,134 \\
\hline & Ağrı & $73,41 \pm 25,95$ & $86,59 \pm 16,84$ & $-2,421$ & 0,015 & 1,205 \\
\hline & Genel sağlık & $65,23 \pm 22,01$ & $69,78 \pm 18,80$ & $-1,284$ & 0,199 & 0,569 \\
\hline \multirow{4}{*}{ MYKÖ } & Emosyonel & $5,45 \pm 1,08$ & $6,10 \pm 0,90$ & $-2,607$ & 0,009 & 1,337 \\
\hline & Fiziksel & $5,39 \pm 1,06$ & $6,01 \pm 0,87$ & $-3,132$ & 0,002 & 1,794 \\
\hline & Sosyal & $5,49 \pm 1,09$ & $6,10 \pm 0,80$ & $-2,653$ & 0,008 & 1,372 \\
\hline & Global & $5,38 \pm 1,06$ & $6,06 \pm 0,82$ & $-3,068$ & 0,002 & 1,729 \\
\hline
\end{tabular}

Cohen's $d$ : İstatistiksel etki büyüklüğü, KF-36: Kısa Form- 36, MYKÖ: Macnew Kalp Hastalığı Sağlıkla İlgili Yaşam Kalitesi Ölçeği, n: katılımcı sayısı, p: istatistiksel anlamlıık düzeyi, SS: Standart Sapma, TKÖ-K: Tampa Kinezyofobi Ölçeği- Kalp, X: Aritmetik Ortalama, Z: Wilcoxon Signed Rank Test katsayısı 


\section{Tartışma ve Sonuç}

Bu çalışma ETKR programının fonksiyonel kapasite, kinezyofobi düzeyi ve yaşam kalitesi üzerine etkisini incelemek üzere planlanmıştır. Bu çalışma, bilgimiz dahilinde, ETKR programına dahil olan bireylerde kinezyofobinin değişimini inceleyen ilk çalışmadır. Çalışmanın sonuçları, ETKR programının KAH hastalarında fonksiyonel kapasiteyi artırmada, kinezyofobi algısını azaltmada ve yaşam kalitesini iyileştirmede etkili olduğunu göstermektedir.

Fonksiyonel kapasite, kardiyovasküler hastalıklarda klinik değerlendirme, prognostik sınıflama ve egzersiz reçetesinin oluşturulmasında kullanılan önemli bir araçtır. Düşük egzersiz kapasitesi mortalitenin belirlenmesinde önemli bir öncüdür [8, 26]. Literatürde yer alan çalışmalar kardiyak rehabilitasyonun fonksiyonel kapasiteyi iyileştirmede etkili olduğu ve egzersiz kapasitesinde meydana gelen her 1 MET'lik artışın, hayatta kalma şansını \%12-17 arttırdığını bildirmişlerdir [8]. Kronik hastalığa sahip bireylerde fonksiyonel kapasitenin geliştirilmesinde kullanılan en önemli farmakolojik olmayan girişim egzersiz eğitimidir [27]. Kardiyak hastalara, kardiyak olayı takiben ya da revaskülarizasyon cerrahisi sonrası dönemde ETKR fonksiyonel kapasitede artış sağlayarak sağ kalımı arttırmaktadır [12]. ETKR programlarının kardiyak hastaların mortalite oranlarını \%21-34 düşürdüğü gösterilmiştir [28]. KABG cerrahisi sonrası ETKR programına dahil olan hastaların 10 yıllık rölatif mortalitelerinin \%46, 10 yıllık kesin mortalitelerinin ise \%12,7 düştüğü tespit edilmiştir [29]. Çalışmamız sonucunda ETKR programına dahil olan KAH hastalarının 6DYT mesafelerinde ve MET değerlerinde istatistiksel olarak anlamlı artış olduğu tespit edilmiştir. Gremeaux ve ark. (2011), KAH hastalarında 6DYT için minimal klinik anlamlıık seviyesini 25 metre olarak belirlemişlerdir [18]. 6DYT mesafesindeki artışın 25 metreden yüksek olması nedeniyle çalışmamızda fonksiyonel kapasitedeki artışın klinik olarak da anlamlı olduğu ve bu nedenle sağ kalım üzerine pozitif etkisi olduğu düşünülmektedir.

Kardiyak olay sonrası KAH hastalarının büyük bir bölümü fiziksel aktivite ve egzersizden kaçınmaktadır. Bu durum rehabilitasyon programlarının başarısını olumsuz yönde etkilemektedir [6]. Egzersizin ve içerisinde birçok bileşeni barındıran KR programlarının, kinezyofobinin önemli nedenleri arasında gösterilen depresyon ve anksiyete gibi psikolojik faktörler üzerine olumlu etkisi olduğu gösterilmiştir [30]. KAH hastalarında kinezyofobi düzeyinin tedavi ve rehabilitasyon süreci üzerine olası etkileri öngörülmesine karşın, literatürde kinezyofobi düzeyini araştıran sınırlı sayıda çalışma bulunmaktadır. Bu çalışmalarda KAH hastalarında TKÖ-K için yüksek kinezyofobi düzeyini gösteren 37 'den fazla olduğu tespit edilmiştir [19, 31]. Çalışmamız sonucunda da katıııcıların başlangıç TKÖK skor ortalamalarııı 37 'den fazla olduğu ve katılımcıların büyük çoğunluğunun yüksek kinezyofobi düzeyine sahip olduğu belirlenmiştir. Başlangıç verileri açısından değerlendirildiğinde çalışmamız sonuçları literatür ile paralellik göstermektedir.

Kinezyofobinin tedavi programları ve tedavi çıktıları üzerine negatif etkisi bilinmesine karşın, literatürde ETKR programının kinezyofobi düzeyi üzerine etkisini gösteren bir çalışmaya rastlanmamıştır. Çalışmamız sonucunda ETKR programının TKÖ-K skorunu düşürdüğü, ancak bu düşüşün istatistiksel olarak anlamlı olmadığı bulunmuştur. Öte yandan ETKR programı ile birlikte yüksek seviye kinezyofobi düzeyine sahip katılımcı sayısındaki azalmanın istatistiksel olarak anlamlı olduğu belirlenmiştir. Yüksek kinezyofobi düzeyine sahip katılımcı sayısında anlamlı azalma olmasına karşın, TKÖ-K skorundaki değişimin istatistiksel olarak anlamlı olmamasının katılımcı sayısının düşük olmasından kaynaklanmış olabileceğini düşünmekteyiz. Bu çalışma ETKR programının kinezyofobi düzeyini azaltmada etkili bir tedavi yaklaşımı olduğunu gösteren bilgimiz dahilindeki ilk çalışmadır.

Kardiyak olay geçiren hastalar, genel popülasyondan daha düşük sağlıkla ilişkili yaşam kalitesine sahiptirler [9]. Bu durum artmış mortalite ve tekrar hastaneye yatış gibi bağımsız değişkenlerle ilişkilidir [32]. Bu açıdan değerlendirildiğinde KR programlarının en önemli amaçlarından biri fonksiyonel kapasiteyi arttırmak kadar, yaşam kalitesini de iyileştirmektir. Literatürde ETKR programlarının sağlıkla ilişkili yaşam kalitesinin fiziksel fonksiyon parametresinde önemli iyileşme sağladığı gösterilmiştir [34]. Çalışmamızda ise ETKR programı sonrası sadece KF-36'nın fiziksel fonksiyon ve ağrı parametresinde istatistiksel olarak anlamlı iyileşme olduğu belirlenmiştir. Saeidi ve ark (2013) da yaptıkları çalışmada, çalışmamızla benzer şekilde ETKR programı sonrası KF-36'nın ağrı parametresinde istatistiksel olarak anlamlı iyileşme sağlandığını bildirmişlerdir [34]. Özellikle KF-36'nın ağıı alt başlığındaki bu iyileşmenin fiziksel fonksiyonda meydana gelen değişime bağlı olduğunu düşünmekteyiz. 
Literatürde ETKR programlarının hastalıkla ilişkili yaşam kalitesini iyileştirmede de etkili olduğu gösterilmiştir. Schönfelder ve ark (2021) yaptıkları çalışmada ETKR programına dahil ettikleri hastaları 3 gruba ayırmış ve farklı egzersiz tiplerini kullanarak aerobik egzersiz yaptırmışlardır. Bu çalışma sonucunda egzersiz tipinden bağımsız olarak tüm katılımcıların ETKR programı sonrası MYKÖ’nün tüm alt başlıklarında istatistiksel olarak anlamlı iyileşme sağladığı belirlenmiştir [35]. Literatürle benzer şekilde çalışmamızda ETKR programı sonrası hastalıkla ilişkili yaşam kalitesi değerlendirmesinde ise MYKÖ'nün tüm alt başlıklarında istatistiksel olarak anlamlı iyileşme olduğu belirlenmiştir. Sağlıkla ilişkili yaşam kalitesini değerlendirmek üzere kullanılan KF-36'nın yalnızca fiziksel fonksiyon ve ağrı alt başıklarında istatistiksel olarak anlamlı iyileşme olmasına karşın, hastalıkla ilişkili yaşam kalitesini değerlendirmek üzere kullanılan MYKÖ’nün tüm alt başlıklarında istatistiksel olarak anlamlı iyileşme olmasının, hastalıkla ilişkili yaşam kalitesini değerlendirme araçlarının ilgili popülasyondaki değişimleri tespit etmedeki hassasiyetinden kaynaklanmış olabileceğini düşünmekteyiz. Ayrıca hastaların gruplar halinde rehabilitasyon programına alınmış olmasının, hastaların sosyal ihtiyaçları üzerine olumlu etki etmiş olabileceğini ve MYKÖ'nün sosyal ve emosyonel alt başlıklarındaki iyileşmelerinde bundan kaynaklanmış olabileceğini düşünmekteyiz.

$\mathrm{Bu}$ çalışmanın birtakım limitasyonları bulunmaktadır. Bunlardan ilki, katıımcıların kardiyak rehabilitasyon programı içerisinde tabi oldukları egzersiz eğitimlerindeki farklılık sonuçlar üzerinde etkili olduğunu düşünmekteyiz. Çalışmaya dahil olan katııımcı sayısı çalışma sonuçları üzerinde etkili olmuş olabilir. Gelecekteki çalışmaların daha yüksek katılımcı sayısı ile planlanmasının kanıt değeri daha yüksek sonuçlar elde etmek adına önemli olduğunu düşünmekteyiz. Ayrıca çalışmamızda fonksiyonel kapasite submaksimal bir test olan 6DYT ile değerlendirilmiştir. Egzersiz kapasitesinin değerlendirilmesinde altın standart olan zirve oksijen tüketiminin belirlenmesi fonksiyonel kapasitedeki değişimin daha objektif olarak ortaya konmasına katkı sağlayacaktır.

\section{Sonuç}

Bu çalışma ETKR programının KAH için önemli bir mortalite belirleyicisi olan fonksiyonel kapasite üzerine etkili olduğunu göstermiştir. Hastaların fonksiyonel kapasitelerindeki ve katıımlarındaki kısıtlamaların en büyük nedenlerinden olan kinezyofobi düzeyini azaltmada ve yaşam kalitesini iyileştirmede de etkili olduğu tespit edilmiştir. KAH hastalarında faz II ETKR programının fonksiyonel kapasite, yaşam kalitesi üzerine etkili olduğunu ve ilgili popülasyonda güvenle reçete edilebileceğini düşünmekteyiz.

\section{Kaynakça}

[1] Naghavi M, Abajobir AA, Abbafati C, et al. Global, regional, and national age-sex specific mortality for 264 causes of death, 1980-2016: a systematic analysis for the Global Burden of Disease Study 2016. Lancet 2017;390:1151-1210.

[2] Townsend N, Wilson L, Bhatnagar P, Wickramasinghe K, Rayner M, Nicholas M. Cardiovascular disease in Europe: epidemiological update 2016. Eur Heart J 2016;37:3232-3245.

[3] Onat A, Can G, Yüksel H, Ademoğlu E, et al. TEKHARF 2017 Tıp dünyasının kronik hastalıklara yaklaşımına öncülük. Istanbul:2017;20-28. Available at: https://file.tkd.org.tr/PDFs/TEKHARF-2017.pdf. Accessed April 2, 2021

[4] Ferreira González I. The epidemiology of coronary heart disease. Rev Esp Cardiol (Engl Ed) 2014;67:139-144.

[5] Quindry JC, Franklin BA, Chapman M, Humphrey R, Mathis S. Benefits and risks of high-intensity interval training in patients with coronary artery disease. Am J Cardiol 2019;123:1370-1377.

[6] Bäck M, Cider A, Herlitz J, Lundberg M, Jansson B. The impact on kinesiophobia (fear of movement) by clinical variables for patients with coronary artery disease. Int J Cardiol 2013;167:391-397.

[7] Bosworth HB, Siegler IC, Olsen MK, et al. Social support and quality of life in patients with coronary artery disease. Qual Life Res 2000;9:829-839.

[8] Myers J, Prakash M, Froelicher V, Do D, Partington S, Atwood JE. Exercise capacity and mortality among men referred for exercise testing. N Engl J Med 2002;346:793-801. 
[9] Bäck M. Exercise and physical activity in relation to kinesiophobia and cardiac risk markers in coronary artery disease. Gothenburg: Aidla Trading AB; 2012. Available at: https://www.sls.se/globalassets/vic/disputerade-medlemmar/mariaback.pdf. Accessed April 5, 2021

[10] Jette DU, Downing J. Health status of individuals entering a cardiac rehabilitation program as measured by the medical outcomes study 36-item short-form survey (SF-36). Phys Ther 1994;74:521-527.

[11] Perk J, Backer GD, Gohlke H, et al. European guidelines on cardiovascular disease prevention in clinical practice (version 2012): the fifth joint task force of the european society of cardiology and other societies on cardiovascular disease prevention in clinical practice (constituted by representatives of nine societies and by invited experts). Eur Heart J 2012;33:1635-1701.

[12] Anderson L, Oldridge N, Thompson DR, et al. Exercise-based cardiac rehabilitation for coronary heart disease: cochrane systematic reiew and meta-analysis. J Am Coll Cardiol 2016;67:1-12.

[13] Lavie CJ, Milani RV. Disparate effects of improving aerobic exercise capacity and quality of life after cardiac rehabilitation in young and elderly coronary patients. J Cardiopulm Rehabil 2000;20:235-240.

[14] Nilsson BB, Lunde P, Grogaard HK, Holm I. Long-term results of high-Intensity exercise-based cardiac rehabilitation in revascularized patients for symptomatic coronary artery disease. Am J Cardiol 2018;121:21-26.

[15] Swank AM, Funk DC, Manire JT, Allard AL, Denny DM. Effect of resistance training and aerobic conditioning on muscular strength and submaximal fitness for individuals with chronic heart failure: influence of age and gender. J Strength Cond Res 2010;24:1298-1305.

[16] Albouaini, K., Egred, M., Alahmar, A., Wright, D. J. Cardiopulmonary exercise testing and its application. Postgrad Med J 2007; 83(985), 675-682.

[17] Hamilton DM, Haennel RG. Validity and reliability of the 6-minute walk test in a cardiac rehabilitation population. J Cardiopulm Rehabil 2000;20:156-164.

[18] Gremeaux V, Troisgros O, Benaim S, et al. Determining the minimal clinically important difference for the six-minute walk test and the 200-meter fast-walk test during cardiac rehabilitation program in coronary artery disease patients after acute coronary syndrome. Arch Phys Med Rehabil 2011;92:611-619.

[19] Acar S, Savci S, Keskinoğlu P, et al. Tampa scale of kinesiophobia for heart Turkish version study: cross-cultural adaptation, exploratory factor analysis, and reliability. J Pain Res 2016;9:445-451.

[20] Vlaeyen JW, Kole Snijders AM, Rotteveel AM, Ruesink R, Heuts PH. The role of fear of movement/(re) injury in pain disability. J Occup Rehabil 1995;5:235-252.

[21] Najafi M, Sheikhvatan M, Montazeri A, Sheikhfathollahi M. Reliability of World Health Organization's Quality of Life-BREF versus Short Form 36 Health Survey questionnaires for assessment of quality of life in patients with coronary artery disease. J Cardiovasc Med (Hagerstown) 2009;10:316-321.

[22] Çelik D, Çoban Ö. Short Form Health Survey version-2.0 Turkish (SF-36v2) is an efficient outcome parameter in musculoskeletal research. Acta Orthop Traumatol Turc 2016;50:558-561.

[23] Daskapan A, Höfer S, Oldridge N, Alkan N, Muderrisoglu H, Tuzun EH. The validity and reliability of the Turkish version of the MacNew Heart Disease Questionnaire in patients with angina. J Eval Clin Pract 2008;14:209-213.

[24] Dixon T, Lim LLY, Oldridge NB. The MacNew heart disease health-related quality of life instrument: reference data for users. Qual Life Res 2002;11:173-183.

[25] Cohen, J.. Statistical Power Analysis for the Behavioral Sciences. 1988. New York, NY: Routledge Academic.

[26] Kavanagh T, Mertens DJ, Hamm LF, et al. Prediction of long-term prognosis in 12169 men referred for cardiac rehabilitation. Circulation 2002;106:666-671.

[27] Gomes Neto M, Duraes AR, Reis HFCD, Neves VR, Martinez BP, Carvalho VO. High-intensity interval training versus moderate-intensity continuous training on exercise capacity and quality of life in patients with coronary artery disease: a systematic review and meta-analysis. Eur J Prev Cardiol 2017;24:1696-1707.

[28] Suaya JA, Stason WB, Ades PA, Normand SLT, Shepard DS. Cardiac rehabilitation and survival in older coronary patients. J Am Coll Cardiol 2009;54:25-33. 
[29] Pack Quinn R, Goel K, Lahr Brian D, et al. Participation in cardiac rehabilitation and survival after coronary artery bypass graft surgery: a community-based study. Circulation 2013;128:590-597.

[30] Lavie CJ, Milani RV, O'Keefe JH, Lavie TJ. Impact of exercise training on psychological risk factors. Prog Cardiovasc Dis 2011;53:464-470.

[31] Tutun Yumin E, Ozel A, Saltan A, Sertel M, Ankaralı H, Tarsuslu Simsek T. Effects of pain, dyspnea, and kinesiophobia on life quality in patients with coronary artery disease. Anatol Klin J Med Sci 2017;22:75-84.

[32] Currie KD, Bailey KJ, Jung ME, McKelvie RS, MacDonald MJ. Effects of resistance training combined with moderate-intensity endurance or low-volume high-intensity interval exercise on cardiovascular risk factors in patients with coronary artery disease. J Sci Med Sport 2015;18:637-642.

[33] He CJ, Zhu CY, Zhu YJ, et al. Effect of exercise-based cardiac rehabilitation on clinical outcomes in patients with myocardial infarction in the absence of obstructive coronary artery disease (MINOCA). Int J Cardiol 2020;315:9-14.

[34] Saeidi M, Mostafavi S, Heidari $\mathrm{H}$, Masoudi S. Effects of a comprehensive cardiac rehabilitation program on quality of life in patients with coronary artery disease. ARYA Atheroscler 2013;9:179-185.

[35] Schönfelder M, Oberreiter H, Egger A, Tschentscher M, Droese S, Niebauer J. Effect of different endurance training protocols during cardiac rehabilitation on quality of life. Am J Med 2021;134:805-811. 